\title{
Mathematical Model for the Dynamics of Glucose, Insulin and $\beta$-Cell Mass under the Effect of Trauma, Excitement and Stress
}

\author{
Isa Ibrahim Mohammed1, Ibrahim Isa Adamu², Seni James Barka ${ }^{3}$ \\ ${ }^{1}$ Department of General Studies, Gombe State College of Health Sciences and Technology, Kaltungo, Gombe State, Nigeria \\ ${ }^{2}$ Department of Mathematics, Modibbo Adama University of Technology, Yola, Adamawa State, Nigeria \\ ${ }^{3}$ Department of Community Health, Gombe State College of Health Sciences and Technology, Kaltungo, Gombe State, Nigeria \\ Email: Kombani45@gmail.com, Ibrahimadamu.iia@gmail.com, barkaseni@gmail.com
}

How to cite this paper: Mohammed, I.I., Adamu, I. and Barka, S.J. (2019) Mathematical Model for the Dynamics of Glucose, Insulin and $\beta$-Cell Mass under the Effect of Trauma, Excitement and Stress. Modeling and Numerical Simulation of Material Science, 9, 71-96.

https://doi.org/10.4236/mnsms.2019.94005

Received: August 11, 2019

Accepted: September 27, 2019

Published: September 30, 2019

Copyright $\odot 2019$ by author(s) and Scientific Research Publishing Inc.

This work is licensed under the Creative

Commons Attribution International

License (CC BY 4.0).

http://creativecommons.org/licenses/by/4.0/

(c) $\underset{\mathrm{EY}}{\mathrm{E}}$ Open Access

\begin{abstract}
In this work, we presented a mathematical model for the dynamics of glucose, insulin and beta-cell mass under the influence of trauma, excitement and/or stress, the model is an improvement on the work by [1]. We defined and incorporated a parameter $\rho$ to represent the effectiveness of epinephrine in suppressing insulin secretion and a parameter $G_{e}$ representing epinephrine induced glucose increase as the factors that affect glucose and insulin homeostasis. The model which consists of a system of three nonlinear ordinary differential equations was used to investigate the effect of epinephrine on glucose, insulin and beta-cell mass dynamics. The result of the study showed that; In the presence of epinephrine, the blood glucose increased and the blood insulin decreased due to suppression by the hormone, despite the fact that there is an increase in beta-cell mass the system remained extremely hyperglycemic. Furthermore, the result of the numerical experiment carried out indicated that frequent epinephrine secretion into the blood induced prolong and extreme hyperglycemia. Frequent epinephrine secretion increases the risk of diabetes in humans. In view of the findings of this study, we recommend that there should be massive and continuous health education, especially for communities living in the areas where the stated agents (trauma, excitement and stress) of epinephrine secretion are common.
\end{abstract}

\section{Keywords}

Mathematical Model, Epinephrine, Prolong Hyperglycemia, Normoglycemia, Beta-Cells, Diabetic with Complication, Equilibrium and Stability 


\section{Introduction}

Diabetes mellitus is the disease of metabolism, which is characterized by very high sugar levels in the blood and urine. The body is unable to metabolize all its sugars due to insufficient supply of insulin. One of the most finely tuned mechanisms of the human body is the regulation of sugar in the blood-stream. A delicate balance is normally maintained between the amounts of glucose and insulin in the bloodstream [2]. Diabetes mellitus can also be defined as a disease of the glucose regulatory system characterized by fasting and/or postprandial hyperglycaemia [3].

According to [1], there are two types of diabetes, namely:

1) Type 1 diabetes;

2) Type 2 diabetes.

\subsection{The Type 1 Diabetes}

Type 1 diabetes (also referred to as juvenile-onset or insulin-dependent diabetes) is due to autoimmune attack on the insulin secreting $\beta$-cells [1]. Type 1 diabetes affects people under the age of 40 , and represents $10 \%$ to $15 \%$ of the diabetic population [4]. Patients with type 1 diabetes are recommended to take insulin injections [1].

\subsection{The Type 2 Diabetes}

Type 2 diabetes (also referred to as adult-onset or non-insulin-dependent diabetes) is associated with a deficit in the mass of $\beta$-cells due to extreme elevated blood glucose level which reduced insulin secretion and resistance to the action of insulin [1]. Type 2 diabetes represents $85 \%$ - $90 \%$ of the diabetic population [4].

The pre-disposing historical high-risk factors for T2DM include increasing age (old age), central obesity, dietary polyphagia of animal fat, carbonate drink, lack of physical exercise, familiar genetic factor, history of gestational diabetes, polycystic ovary syndrome, and severe mental illness, presence of hypertension, hyperlipidaemia, ethnicity and cardio-metabolic factors. Recent emerging risk factors include sleeping deprivation, drug-induced metabolic changes, environmental pollutants, low birth weight and fatal malnutrition [7].

Gestational diabetes can occur temporally during pregnancy which is due to hormonal changes and usually begins in the fifth or sixth month of pregnancy (between the $24^{\text {th }}$ and $28^{\text {th }}$ weeks). Gestational diabetes usually resolves once the baby is born. However, $25 \%-50 \%$ of women with gestational diabetes will eventually develop diabetes later in their life, especially in those who require insulin during pregnancy and those who are overweight after their delivery [1].

\subsection{Aetiology and Progression of Diabetes}

Diabetes mellitus, commonly known as diabetes, is a syndrome of disordered metabolism, usually due to a combination of hereditary and environmental causes, resulting in abnormally high blood sugar levels known as hyperglycemia [8]. 
Blood glucose levels are regulated by two negative feedback loops. In the short term, hyperglycemia stimulates a rapid increase in insulin release from the pancreatic $\beta$-cells. The associated increase in blood insulin levels causes increased glucose uptake and decrease glucose production by the liver leading to a reduction in blood glucose [1]. Recent evidence suggests that chronic hyperglycemia may contribute to a second negative feedback loop by increasing the mass of insulin secreting $\beta$-cells, through changes in the rates of $\beta$-cell replication and death [1]. An increased $\beta$-cell mass represents an increase capacity for insulin secretion which, in turn, would lead to a decrease in blood glucose. Type 2 diabetes has been associated with defects in components of both the short-term and chronic negative feedback loops. Although type 2 diabetes is associated with insulin resistance, insulin secretory defects, and insufficient $\beta$-cell mass, each of these defects can also be found in people without diabetes.

Insulin-stimulated glucose disposal is reduced by $50 \%-100 \%$ in patients with type 2 diabetes as compared to non-diabetic controls. However, insulin resistance of a similar magnitude also has been documented in many no diabetic individuals including obese subjects, or during pregnancy, puberty, and aging [1]. Thus, normoglycemia can be maintained in subjects with insulin resistance via increase in blood insulin levels. Defects of insulin secretion have been demonstrated in some people with type 2 diabetes [1]. Even more severe defects in insulin secretion are present in patients with type 1 diabetes following islet transplantation, when normoglycemia is maintained in the absence of exogenous insulin treatment [1]. This suggests that glucose homeostasis can be maintained despite significant loss of $\beta$-cell function when an individual has normal insulin sensitivity. [1] observed that $\beta$-cell mass is reduced by $40 \%-50 \%$ in patients with type 2 diabetes when compared with weight matched non-diabetic subjects. In comparison, approximately $80 \%-90 \%$ of the $\beta$-cell mass is lost before the onset of hyperglycemia in individuals who develop type 1 diabetes, suggesting that a greater $\beta$-cell mass is required in the presence of insulin resistance [1]. This is also consistent with the observation of a $43 \%$ higher $\beta$-cell mass in normoglycemia for subjects with insulin resistance due to obesity [1]. Although these data suggest that multiple defects are required for the onset of type 2 diabetes, it is unclear if these defects have a single causal origin or if they occur independently. Experimental induction of insulin resistance using either high fat feeding, glucocorticoid administration, or genetically induced obesity has been shown to cause type 2 diabetes under certain circumstances. This supports the hypothesis that insulin resistance can cause $\beta$-cell defects, and hence diabetes, either by overworking the $\beta$-cell ( $\beta$-cell exhaustion) or by toxic effects of hyperglycemia on the $\beta$-cell (glucose toxicity). However, the existence of normoglycemia in humans and animals highly resistant to insulin suggests independent defects in insulin sensitivity and $\beta$-cell function are required for type 2 diabetes. Finally, hyperglycemia is known to induce insulin resistance. This supports the hypothesis that a primary insulin secretory defect that causes hyperglycemia could lead to insulin resistance and diabetes via increased glucose levels [1]. 


\subsection{Symptoms of Diabetes}

According to report by [9], the symptoms of diabetes are as follows:

1) Frequent urination and excessive thirst;

2) Disproportionate thirst;

3) Intense hunger;

4) Weight gain;

5) Unusual weight loss;

6) Increase fatigue;

7) Irritability;

8) Blurred vision;

9) Sexual dysfunction among men;

10) Numberless or tingling, especially in a feet or hands, etc.

\subsection{Diabetes Complications}

Diabetes if not properly controlled it will lead to the following complications:

1) Kidney failure;

2) Blindness;

3) Amputation;

4) Cardiovascular diseases [4].

\section{Model Formulation}

In this section, we developed model glucose, insulin and beta cells dynamics in which we incorporated the effect of trauma, excitement and stress as a factor that affect glucose and insulin homeostasis.

\subsection{Existing Model Equations}

[1] Obtained the model equations describing the $\beta$-cell mass, insulin and glucose dynamics which we described in the figures bellow as in the absence of epinephrine as follows:

$$
\begin{aligned}
& \frac{\mathrm{d} G}{\mathrm{~d} t}=R_{0}-\left(E_{G O}+S_{I} I\right) G, \\
& \frac{\mathrm{d} I}{\mathrm{~d} t}=\frac{\beta \sigma G^{2}}{\alpha+G^{2}}-K I, \\
& \frac{\mathrm{d} \beta}{\mathrm{d} t}=\left(-d+r_{1} G-r_{2} G^{2}\right) \beta
\end{aligned}
$$

\subsection{Assumption of Model}

1) Only trauma, excitement and stress are factors that trigger epinephrine secretion from kidney;

2) Epinephrine induced glucose production from kidney is negligible and ignored;

3) Epinephrine induced glucose production from the liver is considered;

4) Blood insulin level will also be decreased by Epinephrine suppression on insulin secretion. 


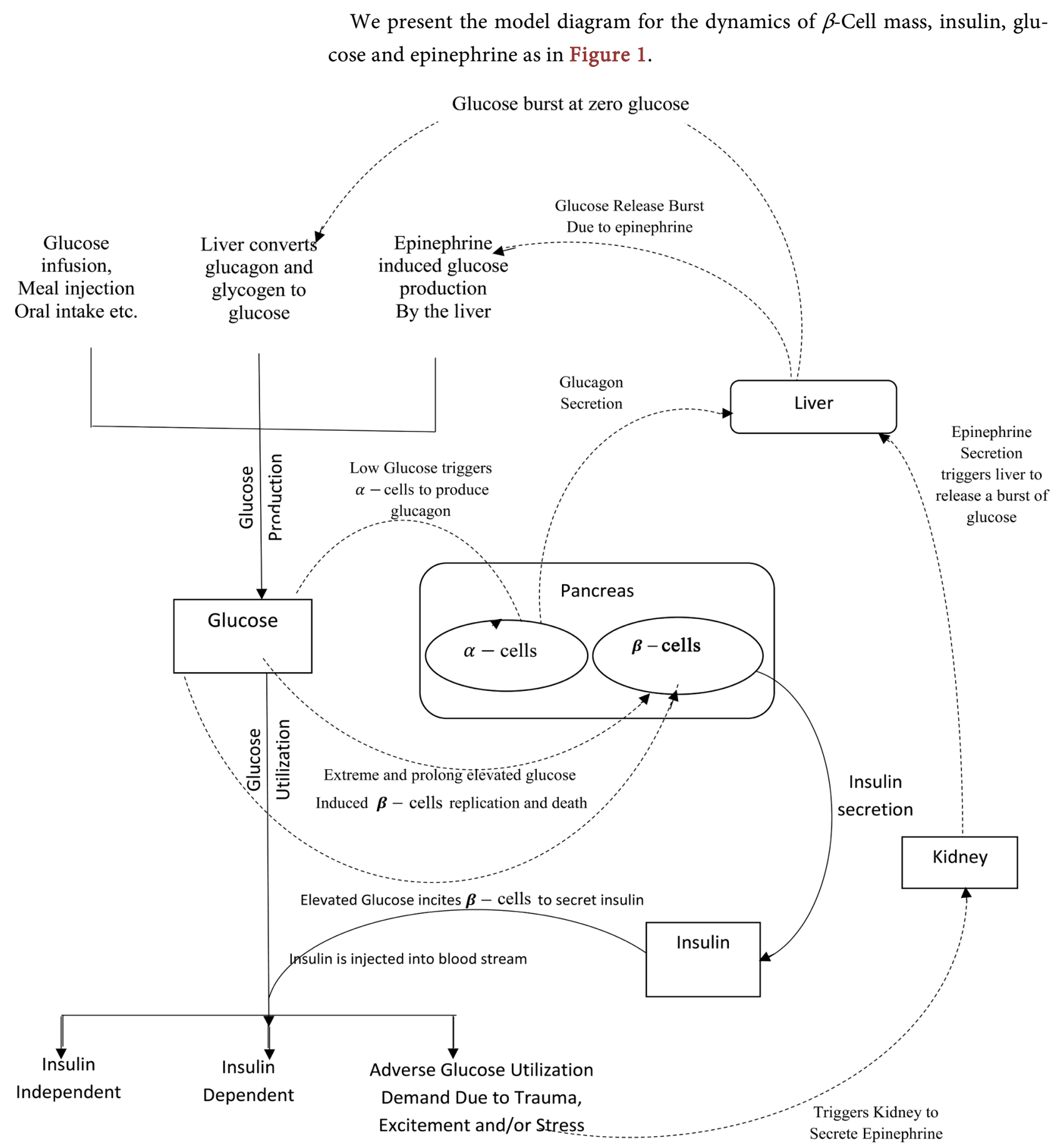

Figure 1. Model diagram for the dynamics of glucose, insulin, beta-cell mass and epinephrine.

\section{Modified Model Equations}

\subsection{Glucose Dynamics}

\subsubsection{Model's Formulation}

In post-absorptive state, the glucose is released into the blood by the liver and kidneys, removed from the interstitial fluid by all the cells of the body, and distributed into many physiological compartments (e.g. arterial blood, venous blood, 
cerebral spinal fluid, interstitial fluid). These studies suggest that a single compartment model is appropriate when glucose kinetics is relatively slow. Since we are primarily concerned with the evolution of fasting blood glucose levels over a time-scale of days to years, glucose dynamics are modeled with a single compartment mass balance equation [1].

$$
\frac{\mathrm{d} G}{\mathrm{~d} t}=\text { production }- \text { utilization }
$$

where $G$ is the concentration of glucose in the blood, and $t$ is the time (measured in days).

\subsubsection{Glucose Production}

The rates of glucose production and utilization are normalized by the volume of glucose distribution to obtain the proper units [1]. Thus

$$
\text { production }=P_{0}-\left(E_{G O P}+S_{I P} I\right) G
$$

where $P_{0}$ is the rate of glucose production at zero glucose level, $S_{I P}$ is the glucose effectiveness at zero insulin for production, $S_{I P}$ is insulin sensitivity for production, $I$ is insulin concentration at a time $t$, and $G$ is glucose concentration at a time $t$.

In an emergency situation (induced trauma, excitement and/or stress), the body releases an amount of epinephrine which quickly increases the concentration of glucose in the blood [2].

According to [5] during the infusion of epinephrine alone, plasma glucose concentrations quickly rose and within 1 hour reached a plateau value of $\sim 140$ $\mathrm{mg} / \mathrm{dl}$. Epinephrine is released by the adrenal medulla at a basal endogenous rate of approximately $0.18(\mu \mathrm{g} / \mathrm{min})$ and the epinephrine release modifier varies from 1 to 19.75 . Meaning that, the epinephrine release rate will be 19.75 times the basal release rate with maximal exercise [10].

So let assume that the amount of the basal epinephrine release rate with maximal exercise be into the blood stream due to excitement, trauma and/or stress and let $G_{e}$ be the amount of glucose production due to the effect of epinephrine. Then $G_{e}$ increases the glucose concentration in the blood stream, we incorporate $G_{e}$ into glucose production equation developed by [1].

Hence Equation (3) becomes:

$$
\text { production }=P_{0}+G_{e}-\left(E_{G O P}+S_{I P} I\right) G
$$

where $P_{0}$ is the rate of glucose production at zero glucose level, $G_{e}$ is the amount of glucose production from the breakdown of glycogen due to epinephrine secretion, $E_{G O P}$ is the glucose effectiveness at zero insulin for production and $S_{I P}$ is insulin sensitivity for production.

\subsubsection{Glucose Utilization}

The rates of glucose production and utilization depend on blood glucose and insulin levels. At constant insulin levels, glucose production decreases while up- 
take increases, both linearly with respect to glucose levels [1], we have:

$$
\text { utilization }=U_{0}+\left(E_{G O U}+S_{I U} I\right) G
$$

where $U_{0}$ the rate of glucose utilization at zero glucose level, $E_{G O U}$ is glucose effectiveness at zero insulin for utilization, $S_{I U}$ is insulin sensitivity for utilization, $G$ represents glucose concentration and I represents blood insulin concentrations.

Epinephrine has effect on glucose utilization; however it is negligible and therefore ignored. Substituting Equations (3.4) and (3.5) into Equation (3.2),

$$
\frac{\mathrm{d} G}{\mathrm{~d} t}=\text { production }- \text { utilization } .
$$

We get the following

$$
\begin{aligned}
& \frac{\mathrm{d} G}{\mathrm{~d} t}=P_{0}+G_{e}-\left(E_{G O P}+S_{I P} I\right) G-U_{0}-\left(E_{G O U}+S_{I U} I\right) G \\
& \frac{\mathrm{d} G}{\mathrm{~d} t}=\left(P_{0}-U_{0}\right)+G_{e}-\left[\left(E_{G O P}+E_{G O U}\right)+\left(S_{I P} I+S_{I U} I\right)\right] G
\end{aligned}
$$

Hence, the equation of glucose dynamics under the influence of epinephrine hormones which is secreted in response to trauma, excitement and/or stress is given by

$$
\frac{\mathrm{d} G}{\mathrm{~d} t}=R_{0}+G_{e}-\left(E_{G O}+S_{I} I\right) G
$$

where $R_{0}=P_{0}-U_{0}$ in Table 1 is the net rate of glucose production and at zero glucose level, $G_{e}$ is the amount of glucose increase due to epinephrine hormones,

\begin{tabular}{|c|c|}
\hline Variable/Parameter & Description \\
\hline$G(t)$ & Blood glucose concentration at time $t$ \\
\hline$I(t)$ & Blood insulin concentration at time $t$ \\
\hline$\beta(t)$ & Beta cell mass at time $t$ \\
\hline$R_{0}$ & The net rate of glucose production at zero glucose level \\
\hline$E_{G O}$ & Total glucose effectiveness at zero insulin \\
\hline$S_{I}$ & Total insulin sensitivity \\
\hline$\sigma$ & Maximum rate of insulin secretion \\
\hline$\alpha$ & Inflection point of sigmoidal function \\
\hline$K$ & Insulin clearance rate for muscles, liver and kidney \\
\hline$d_{0}$ & Beta cell natural death rate \\
\hline$r_{1}$ and $r_{2}$ & Constant beta cell glucose tolerance ranges \\
\hline$\rho$ & Epinephrine effectiveness in suppressing insulin secretion \\
\hline$G_{e}$ & Amount of glucose increase due to epinephrine secretion \\
\hline
\end{tabular}
$E_{G O}=E_{G O P}-E_{G O U}$ in Table 1 is total glucose effectiveness at zero insulin for production and utilization, and $S_{I}=S_{I P}+S_{I U}$ in Table 1 is the total insulin sensitivity for production and utilization.

Table 1. Definition of variables and parameters of the model. 


\subsection{Insulin Dynamics}

Insulin is secreted by pancreatic $\beta$-cell, cleared by the liver, kidneys, and insulin receptors, and distributed into several compartments (e.g. Portal vein, peripheral blood, and interstitial fluid) of the body. Our main concern is the long-time evolution of fasting insulin levels in peripheral blood. Since the dynamics of fasting insulin levels on this time-scale are slow, we use a single-compartment equation given by

$$
\frac{\mathrm{d} I}{\mathrm{~d} t}=\text { Secretion }- \text { Clearance }
$$

where Secretion and Clearance are rates normalized by insulin's volume of distribution [1].

\section{Insulin secretion}

The rate of insulin secretion from pancreatic $\beta$-cells is a sigmoidal function of glucose production [1]. Hence, we have

$$
\frac{\mathrm{d} I}{\mathrm{~d} t}=\frac{\beta \sigma G^{2}}{\alpha+G^{2}}
$$

where $\beta$ is the mass of pancreatic $\beta$-cells, all $\beta$-cells are assumed to secrete insulin at the same maximal rate $\sigma, \alpha$ is a constant and $\frac{G^{2}}{\alpha+G^{2}}$ is a Hill function that describes the sigmoid nature of insulin secretion [1].

When epinephrine is secreted into the blood stream, the insulin secretion by pancreatic $\beta$-cells will be suppressed by $41 \%$ [5]. This means insulin sensitivity to trigger glucose utilization by cells will be reduced. Let $\rho$ be amount of insulin suppression by epinephrine, then we have a negative effect on insulin secretion thus:

$$
\text { Amount of Insulin secretion suppressed }=-\rho I
$$

Since $\rho$ is the epinephrine effectiveness in suppressing insulin secretion. We incorporate $(-\rho I)$ to insulin secretion in Equation (3.9) to obtain the total insulin secretion when epinephrine is secreted. Therefore, the rate of insulin secretion in the presence of epinephrine secretion is given by

$$
\frac{\mathrm{d} I}{\mathrm{~d} t}=\frac{\beta \sigma G^{2}}{\alpha+G^{2}}-\rho I
$$

\section{Insulin Clearance}

The rate of insulin clearance is proportional to blood insulin levels when the system is near steady state [1]. Clearance $\propto I$

Thus,

$$
\text { Clearance }=K I
$$

where $K$ is the insulin clearance constant by liver, kidney, muscle, and insulin receptors [1].

Substituting Equations (3.10) and (3.11) into Equation (3.7), we obtain the equation governing insulin secretion and clearance in the presence of epineph- 
rine, as

$$
\begin{aligned}
& \frac{\mathrm{d} I}{\mathrm{~d} t}=\frac{\beta \sigma G^{2}}{\alpha+G^{2}}-\rho I-K I \\
& \frac{\mathrm{d} I}{\mathrm{~d} t}=\frac{\beta \sigma G^{2}}{\alpha+G^{2}}-(\rho+K) I
\end{aligned}
$$

where $\beta$ is the mass of pancreatic $\beta$-cells. $\sigma$ is a rate of maximum secretion by the pancreatic $\beta$-cells and $\frac{G^{2}}{\alpha+G^{2}}$ Hill function that describes the sigmoid ranging from 0 to $1, \rho$ is the parameter incorporated to insulin secretion which is epinephrine effectiveness in suppressing insulin secretion, and $K$ is insulin clearance constant by liver, kidney, muscle, and insulin receptors, and $\mathrm{I}$ is insulin.

\section{3. $\beta$-Cell Mass Dynamics}

Despite a complex distribution of pancreatic $\beta$-cells throughout the pancreas, $\beta$-cell mass dynamics have been successfully quantified with a single compartment model [1].

$$
\frac{\mathrm{d} \beta}{\mathrm{d} t}=\text { Formation }- \text { Loss }
$$

where Formation and Loss represent the rates at which $\beta$-cell mass is added to or removed from the population, respectively [1].

\subsubsection{Replication of $\beta$-Cells}

New $\beta$-cells can be formed by replication of existing $\beta$-cells. In vitro studies show that the percentage of $\beta$-cells undergoing replication varies as a nonlinear function of glucose level in the medium. Replication rates for $\beta$-cell mass increase with increasing glucose levels. However, at extreme hyperglycemia, $\beta$-cells replication may be reduced. We modeled this behaviour with a simple second degree polynomial (patterned after logistic growth) [1].

$$
\text { Replication }=\left(r_{1 r} G-r_{2 r} G^{2}\right) \beta
$$

where $r_{1 r}$ and $r_{2 r}$ are constants in Table 1.

\subsubsection{Loss of $\beta$-Cells}

Cells can be lost from the $\beta$-cell mass by apoptosis (regulated cell death), necrosis (unregulated cell death). In vitro, $\beta$-cells death has been shown to vary nonlinearly with glucose. Increasing the glucose level from 0 to approximately 11 $\mathrm{mM}$ in medium surrounding cultured $\beta$-cells reduced the rate of $\beta$-cells death. Above $11 \mathrm{mM}$ glucose, the rate of $\beta$-cells death either remained low or increased. We have modeled this behavour with a simple second degree polynomial,

$$
\text { Death }=\left(d_{0}-r_{1 a} G+r_{2 a} G^{2}\right) \beta
$$

where $d_{0}$ is the death rate at zero glucose and $r_{1 a}$ and $r_{2 a}$ are constants.

Substituting Equations (3.14) and (3.15) into Equation (3.13), we obtain the 
equation for $\beta$-cell mass dynamics as:

$$
\frac{\mathrm{d} \beta}{\mathrm{d} t}=\left(-d_{0}+r_{1} G-r_{2} G^{2}\right) \beta
$$

where $r_{1}=r_{1 r}+r_{1 a}$ and $r_{2}=r_{2 r}+r_{2 a}$ are constants in Table 1 related to $\beta$-cell dynamics.

Therefore, from the assumptions, description and the schematic diagram of the modified model in Figure 1, we derived the following modified model equations and we described it as in the presence of epinephrine:

$$
\begin{aligned}
& \frac{\mathrm{d} G}{\mathrm{~d} t}=R_{0}+G_{e}-\left(E_{G O}+S_{I} I\right) G \\
& \frac{\mathrm{d} I}{\mathrm{~d} t}=\frac{\beta \sigma G^{2}}{\alpha+G^{2}}-(\rho+K) I \\
& \frac{\mathrm{d} \beta}{\mathrm{d} t}=\left(-d_{0}+r_{1} G-r_{2} G^{2}\right) \beta
\end{aligned}
$$

\section{Analytical Study}

In this section, we carried out analytical and numerical studies on the modified model which is an extension of [1] model as indicated below:

\subsection{Equilibrium Points of the System}

We studied the equilibrium solution of the system in Equation (3.17) by splitting the glucose regulatory system into subsystems; slow ( $\beta$-cell mass) subsystems and fast (glucose/insulin) subsystems.

From Equation (3.17) we have

$$
\begin{aligned}
& \frac{\mathrm{d} G}{\mathrm{~d} t}=R_{0}+G_{e}-\left(E_{G O}+S_{I} I\right) G \\
& \frac{\mathrm{d} I}{\mathrm{~d} t}=\frac{\beta \sigma G^{2}}{\left(\alpha+G^{2}\right)}-(\rho-K) I \\
& \frac{\mathrm{d} \beta}{\mathrm{d} t}=\left(-d_{0}+r_{1} G-r_{2} G^{2}\right) \beta
\end{aligned}
$$

\subsection{Equilibrium of the Slow Subsystems $\beta$-Cell Mass}

Putting

$$
\frac{\mathrm{d} \beta}{\mathrm{d} t}=0
$$

We have the following:

$$
\begin{gathered}
\quad\left(-d_{0}+r_{1} G-r_{2} G^{2}\right) \beta=0 \\
\text { Either } \beta=0 \text { or }\left(-d_{0}+r_{1} G-r_{2} G^{2}\right)=0
\end{gathered}
$$

We have

$$
r_{2} G^{2}-r_{1} G+d_{0}=0
$$


Solving for $G$

$$
G_{1,2}=\frac{r_{1} \pm \sqrt{r_{2}^{2}-4 \times r_{1} \times d_{0}}}{2 r_{2}}
$$

Either

$$
G_{1}=\frac{r_{1}+\sqrt{r_{2}^{2}-4 \times r_{1} \times d_{0}}}{2 r_{2}}
$$

or

$$
G_{2}=\frac{r_{1}-\sqrt{r_{2}^{2}-4 \times r_{1} \times d_{0}}}{2 r_{2}}
$$

\subsection{Equilibrium of Fast (Glucose/Insulin) Subsystems}

Equating $\frac{\mathrm{d} G}{\mathrm{~d} t}=\frac{\mathrm{d} I}{\mathrm{~d} t}=0$

We have

$$
\frac{\beta \sigma G^{2}}{\left(\alpha+G^{2}\right)}-(\rho-K) I=0
$$

From 4.1, $\beta=0$ hence 4.2 gives

$$
I=0
$$

For glucose dynamics

At equilibrium point, we have

$$
R_{0}+G_{e}-\left(E_{G O}+S_{I} I\right) G=0
$$

Using 4.3 in 4.4 , we have

$$
\begin{aligned}
& R_{0}+G_{e}-E_{G O} G=0 \\
& E_{G O} G=R_{0}+G_{e} \\
& G=\frac{R_{0}+G_{e}}{E_{G O}}
\end{aligned}
$$

Therefore, the equilibrium point of the fast (glucose/insulin) subsystems is given by

$$
G^{*}, I^{*}=\left(\frac{R_{0}+G_{e}}{E_{G O}}, 0\right)
$$

\subsection{Stability Analysis}

From Equation (3.17) we should find the stability of the fast (glucose/insulin) subsystems

$$
\begin{gathered}
\frac{\mathrm{d} G}{\mathrm{~d} t}=R_{0}+G_{e}-\left(E_{G O}+S_{I} I\right) G \\
\frac{\mathrm{d} I}{\mathrm{~d} t}=\frac{\beta \sigma G^{2}}{\alpha+G^{2}}-(\rho+K) I
\end{gathered}
$$


Using Jacobian Matrix to find the stability

$$
J=\left[\begin{array}{ll}
\frac{\partial F_{1}}{\partial G} & \frac{\partial F_{1}}{\partial I} \\
\frac{\partial F_{2}}{\partial G} & \frac{\partial F_{2}}{\partial I}
\end{array}\right]
$$

Let $F_{1}=R_{0}+G_{e}-\left(E_{G O}+S_{I} I\right) G$ and

$$
F_{2}=\frac{\beta \sigma G^{2}}{\alpha+G^{2}}-(\rho+K) I
$$

Therefore, the Jacobian matrix in (4.5) becomes

$$
J=\left[\begin{array}{cc}
-\left(E_{G O}+S_{I} I\right) & -S_{I} G \\
\frac{-2 \alpha \beta \sigma G}{\left(\alpha+G^{2}\right)^{2}} & -(\rho+K)
\end{array}\right]
$$

At equilibrium of the fast subsystems

$$
J_{0}=\left[\begin{array}{cc}
-E_{G O} & -S_{I} \frac{\left(R_{0}+G_{e}\right)}{E_{G O}} \\
0 & -(\rho+K)
\end{array}\right]
$$

Using characteristics equation.

We have

$$
\left|J\left(E_{o}\right)-\lambda I\right|=0
$$

Putting the Jacobian into characteristics equation

$$
\begin{aligned}
& \left|\left(\begin{array}{cc}
-E_{G O} & -S_{I} \frac{\left(R_{0}+G_{e}\right)}{E_{G O}} \\
0 & -(\rho+K)
\end{array}\right)-\lambda\left(\begin{array}{ll}
1 & 0 \\
0 & 1
\end{array}\right)\right|=0 \\
& \left|\begin{array}{cc}
-E_{G O}-\lambda & -S_{I} \frac{\left(R_{0}+G_{e}\right)}{E_{G O}} \\
0 & -(\rho+K)-\lambda
\end{array}\right|=0 \\
& \left(-E_{G O}-\lambda\right)(-(\rho+K)-\lambda)=0 \\
& -E_{G O}-\lambda=0 \text { or }-(\rho+K)-\lambda=0 \\
& \lambda_{1}=-E_{G O} \text { and } \lambda_{2}=-(\rho+K)
\end{aligned}
$$

Therefore, the fast (Glucose and Insulin) subsystem is locally and asymptotically stable since all the values of $\lambda_{i}<0$ for $i=1,2$ were negative.

For slow ( $\beta$-cell mass) subsystem, we have the following: either $\beta=0$ or $-d_{0}+r_{1} G-r_{2} G^{2}=0$

$$
\lambda=-d_{0}+r_{1} G-r_{2} G^{2}
$$

The slow ( $\beta$-cell mass) subsystems is locally and asymptotically stable since the Eigenvalue was negative, at $r_{2} G^{2}+d_{0}>r_{1} G$.

Since the values of $\mathrm{h} \quad r_{2}=0.0000024$ are in Table 2 . We substituted the values 
Table 2. Values of the parameters and variables of the model; some were obtained from existing model while the remaining values from other literatures.

\begin{tabular}{|c|c|c|c|}
\hline Parameters & Value & & Unit \\
\hline$\stackrel{*}{G}$ & 600 & $\mathrm{mgd} / \mathrm{dl}$ & {$[1]$} \\
\hline${ }_{I}^{*}$ & 284.21 & $\mu \mathrm{Um} / \mathrm{dl}$ & {$[1]$} \\
\hline$\stackrel{*}{\beta}$ & $G=100$ or 250 & $\mathrm{mgdl} / \mathrm{dl}$ & {$[1]$} \\
\hline$\beta_{1}$ & 300 & $\operatorname{mgdl} /$ day & Assumed \\
\hline$\beta_{2}$ & 600 & mgdl/day & Assumed \\
\hline$\beta_{3}$ & 900 & mgdl/day & Assumed \\
\hline$R_{0}$ & 864 & $\mathrm{mgd} / \mathrm{dl}$ & {$[1]$} \\
\hline$E_{G O}$ & 1.44 & $\mathrm{~d}^{-1}$ & {$[1]$} \\
\hline$S_{I}$ & 0.72 & $\mathrm{ml} \mu / \mathrm{dU}$ & {$[1]$} \\
\hline$\sigma$ & 43.2 & $\mu \mathrm{Um} / \mathrm{dl}$ & {$[1]$} \\
\hline$\alpha$ & 20,000 & $\mathrm{mg}^{2} \mathrm{dl} / \mathrm{l}^{2}$ & {$[1]$} \\
\hline$K$ & 432 & $\mathrm{~d}^{-1}$ & {$[1]$} \\
\hline$d_{0}$ & 0.06 & $\mathrm{~d}^{-1}$ & [1] \\
\hline$r_{1}$ & 0.00084 & $\mathrm{mdl} / \mathrm{dg}$ & {$[1]$} \\
\hline$r_{2}$ & $0.24 \times 10^{-5}$ & $\mathrm{mgl}^{2} / \mathrm{dg}^{2}$ & {$[1]$} \\
\hline$G_{e}$ & 140 & $\mathrm{mgd} / \mathrm{dl}$ & {$[5]$} \\
\hline$\rho$ & $41 \%$ & $\mu \mathrm{Um} / \mathrm{dl}$ & {$[6]$} \\
\hline
\end{tabular}

in Table 2 into (4.1) we have

$$
\begin{gathered}
-0.06+0.00084 G-0.0000024 G^{2}=0 \\
24 G^{2}-8400 G+600000=0
\end{gathered}
$$

Putting the above quadratic equation in (4.2), we have

$$
G_{1,2}=\frac{8400 \pm \sqrt{8400^{2}-4 \times 24 \times 600000}}{2 \times 24}
$$

Either

$$
G_{1}=\frac{12000}{48}=250
$$

or

$$
G_{2}=\frac{4800}{48}=100
$$

The one dimensional subsystem had three steady state solutions which were $\beta=0, G=100$ and $G=250$. These three steady states were referred to as the 
pathological, physiological and unstable steady state [1].

Analysing the system as a whole, consider (3.17) above

$$
\begin{aligned}
& F_{1}=R_{0}+G_{e}-\left(E_{G O}+S_{I} I\right) G \\
& F_{2}=\frac{\beta \sigma G^{2}}{\left(\alpha+G^{2}\right)}-(\rho-K) I \\
& F_{3}=\left(-d_{0}+r_{1} G-r_{2} G^{2}\right) \beta
\end{aligned}
$$

Thus, the Jacobian Matrix Jof the above system is given by

$$
\begin{gathered}
J=\left(\begin{array}{ccc}
\frac{\partial F_{1}}{\partial G} & \frac{\partial F_{1}}{\partial I} & \frac{\partial F_{1}}{\partial \beta} \\
\frac{\partial F_{2}}{\partial G} & \frac{\partial F_{2}}{\partial I} & \frac{\partial F_{2}}{\partial \beta} \\
\frac{\partial F_{3}}{\partial G} & \frac{\partial F_{3}}{\partial I} & \frac{\partial F_{3}}{\partial \beta}
\end{array}\right) \\
J=\left(\begin{array}{ccc}
-\left(E_{G O}+S_{I} I\right) & -S_{I} G & 0 \\
\frac{-2 \alpha \beta \sigma G}{\left(\alpha+G^{2}\right)^{2}} & -(\rho+K) & \frac{\sigma G^{2}}{\alpha+G^{2}} \\
\left(r_{1}-2 r_{2} G\right) \beta & 0 & \left(-d_{0}+r_{1} G-r_{2} G^{2}\right)
\end{array}\right)
\end{gathered}
$$

At equilibrium points, the whole system becomes

$$
J\left(E_{0}\right)=\left(\begin{array}{ccc}
-E_{G O} & -S_{I} \frac{\left(R_{0}+G_{e}\right)}{E_{G O}} & 0 \\
0 & -(\rho+K) & \frac{\sigma\left(R_{0}+G_{e}\right)^{2}}{\alpha E_{G O}-\left(R_{0}+G_{e}\right)^{2}} \\
0 & 0 & -d_{0}+r_{1} \frac{\left(R_{0}+G_{e}\right)}{E_{G O}}-r_{2} \frac{\left(R_{0}+G_{e}\right)^{2}}{E_{G O}}
\end{array}\right)
$$

The characteristics equation is given by

$$
\left|J\left(E_{o}\right)-\lambda I\right|=0
$$

$$
\begin{aligned}
& \left|\begin{array}{ccc}
-E_{G O}-\lambda & -S_{I} \frac{\left(R_{0}+G_{e}\right)}{E_{G O}} & 0 \\
0 & -(\rho+K)-\lambda & \frac{\sigma\left(R_{0}+G_{e}\right)^{2}}{\alpha E_{G O}-\left(R_{0}+G_{e}\right)^{2}} \\
0 & 0 & -d_{0}+r_{1} \frac{\left(R_{0}+G_{e}\right)}{E_{G O}}-r_{2} \frac{\left(R_{0}+G_{e}\right)^{2}}{E_{G O}}-\lambda
\end{array}\right|=0 \\
& -E_{G O}-\lambda\left|\begin{array}{cc}
-(\rho+K)-\lambda & \frac{\sigma\left(R_{0}+G_{e}\right)^{2}}{\alpha E_{G O}+\left(R_{0}+G_{e}\right)^{2}} \\
0 & -d_{0}+r_{1} \frac{\left(R_{0}+G_{e}\right)}{E_{G O}}-r_{2} \frac{\left(R_{0}+G_{e}\right)}{E_{G O}}-\lambda
\end{array}\right|
\end{aligned}
$$


Therefore,

$$
\lambda_{1}=-E_{G O}, \lambda_{2}=-(\rho+K) \text { and } \lambda_{3}=-\left(d_{0}+r_{2} \frac{\left(R_{0}+G_{e}\right)}{E_{G O}}-r_{1} \frac{\left(R_{0}+G_{e}\right)}{E_{G O}}\right)
$$

Since all the values of $\lambda_{i}<0$ for $i=1,2,3$ the whole system is locally and asymptotically stable.

The results of the performance of the existing and modified models are shown in Figures 2-15 and MATLAB 2015a was being used to generate the simulations.

\section{Discussion}

Discussion of the results of the study is presented as follows:

Case 1: Glucose dynamics in the absence of epinephrine.

Figure 2 shows the net rate of glucose production at basal glucose level in the absence of epinephrine. This result was obtained by implementing the model under normal glucose, insulin dynamics without trauma, excitement and stress. At basal glucose level, the $\alpha$-cells of the pancreas produce glucagons which trigger the liver to convert stored glycogen into glucose and release it into the blood.

Case 2: Glucose dynamics in the presence of epinephrine.

Figure 3 shows the glucose production at basal glucose level in the presence of trauma, excitement and stress. This result was obtained by implementing the model under normal glucose, insulin dynamics with epinephrine as a result trauma and excitement and stress. At basal glucose level, the adrenal medulla of

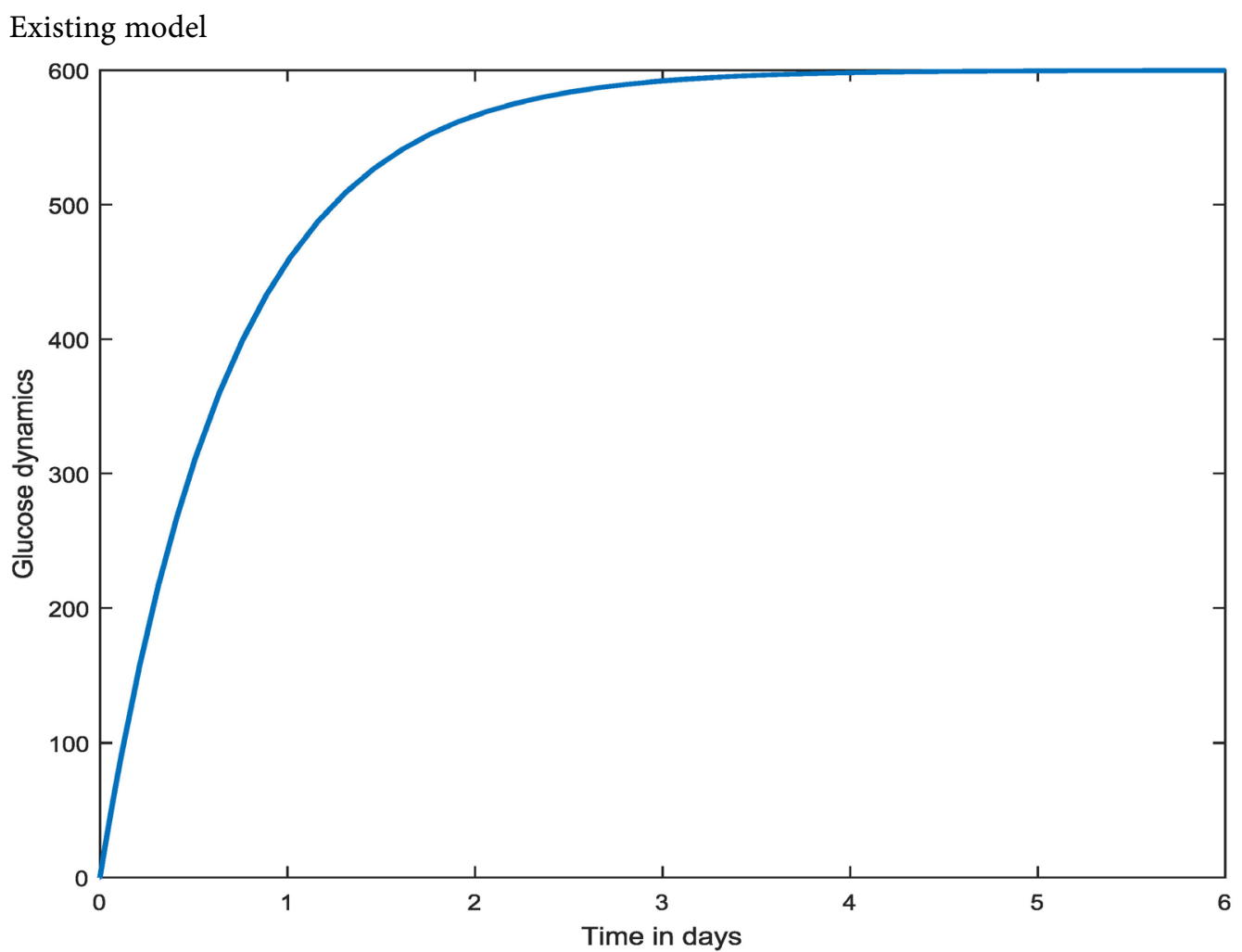

Figure 2. Glucose dynamics in the absence of epinephrine. 
Modified model

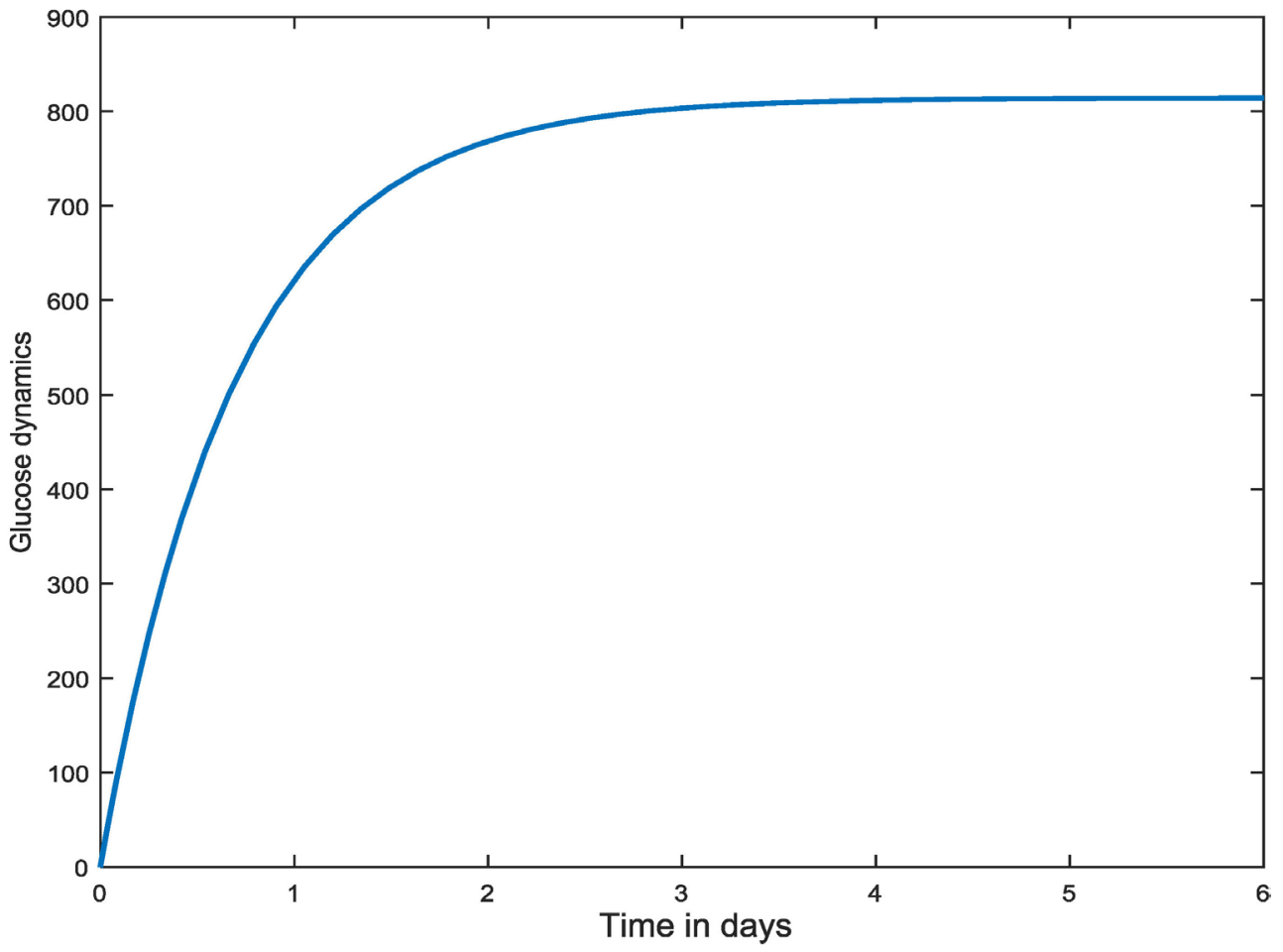

Figure 3. Glucose dynamics in the presence of epinephrine.

Existing model

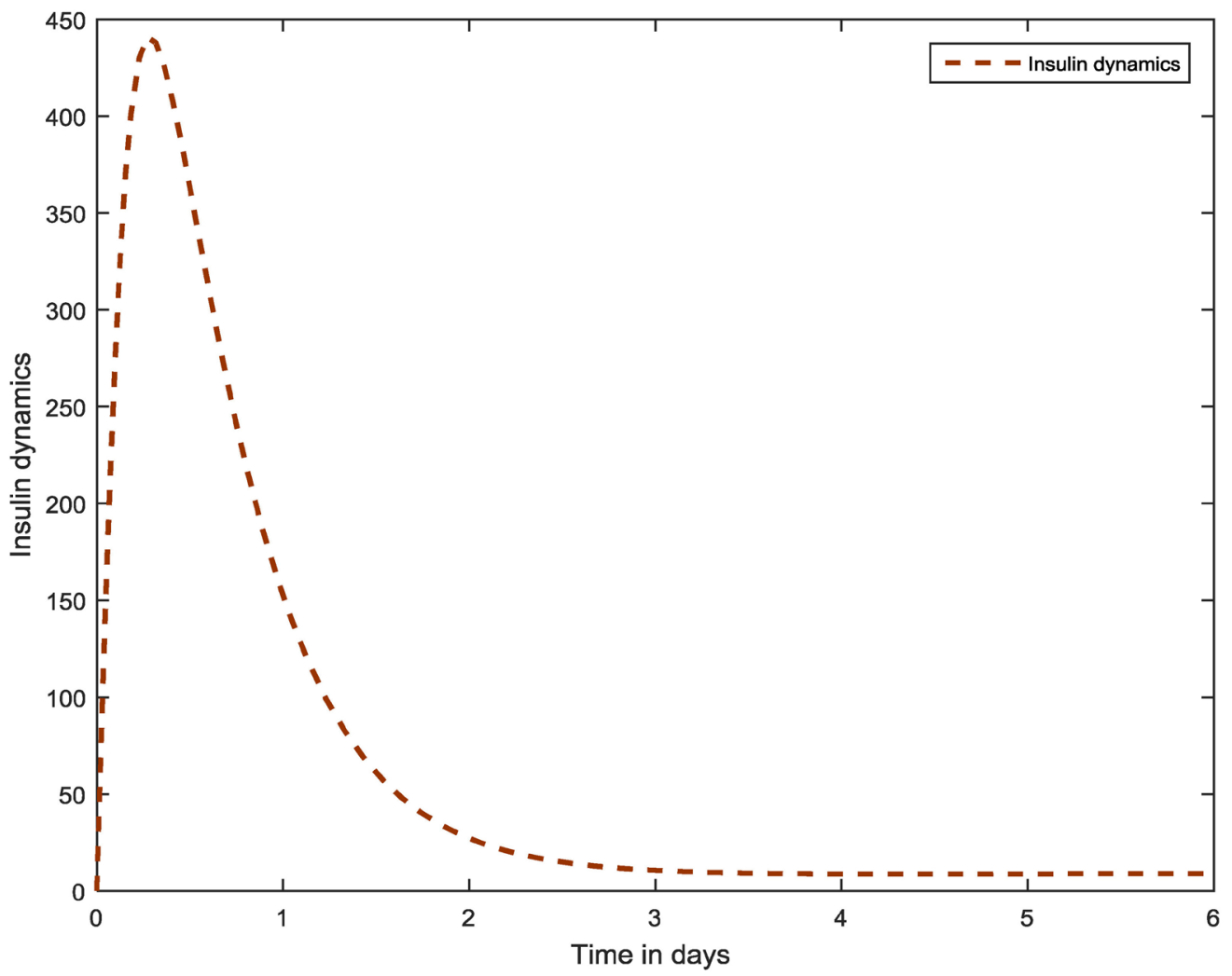

Figure 4. Insulin dynamics in the absence of epinephrine. 
Modified model

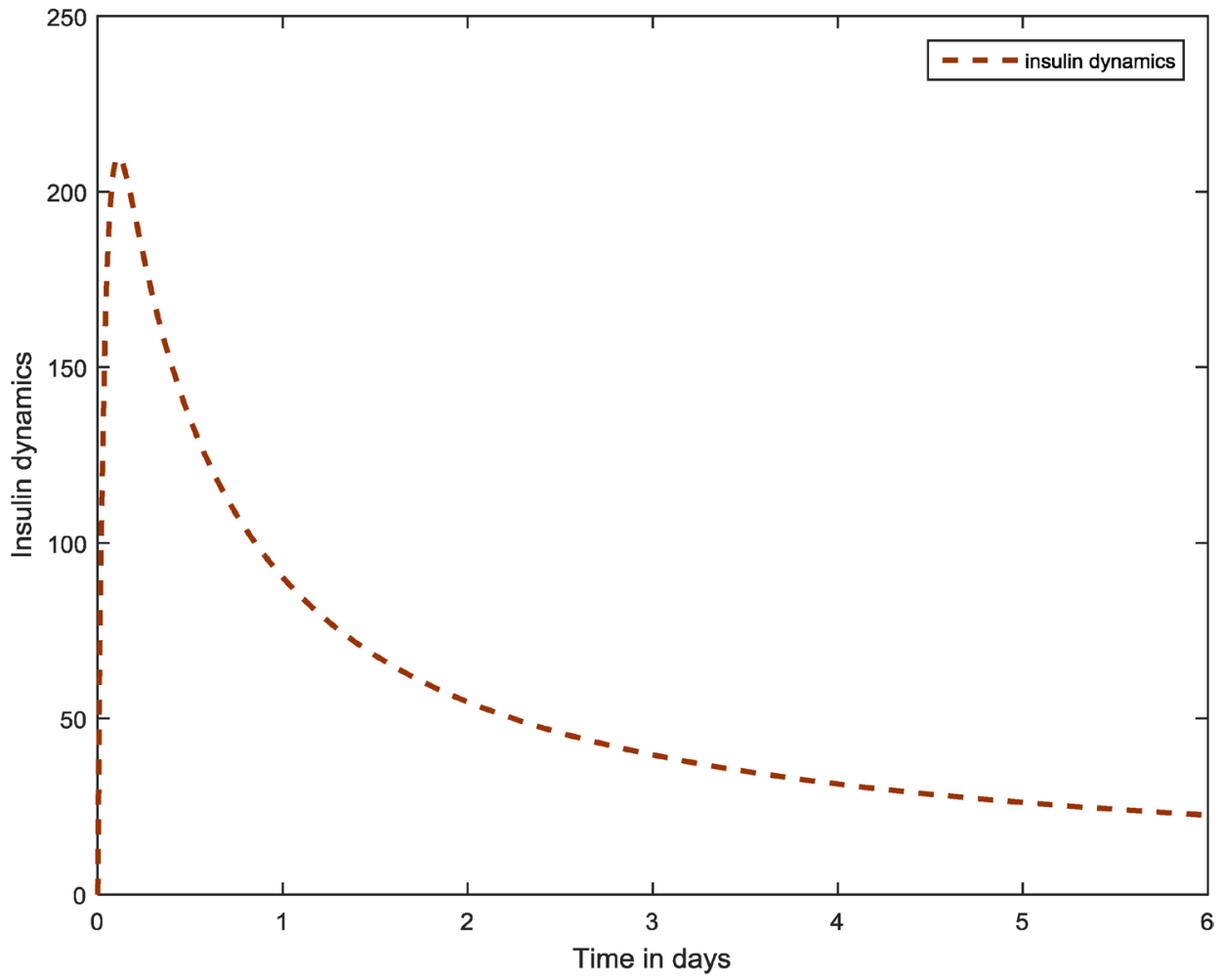

Figure 5. The dynamics of insulin in the presence of epinephrine.

Modified and existing models

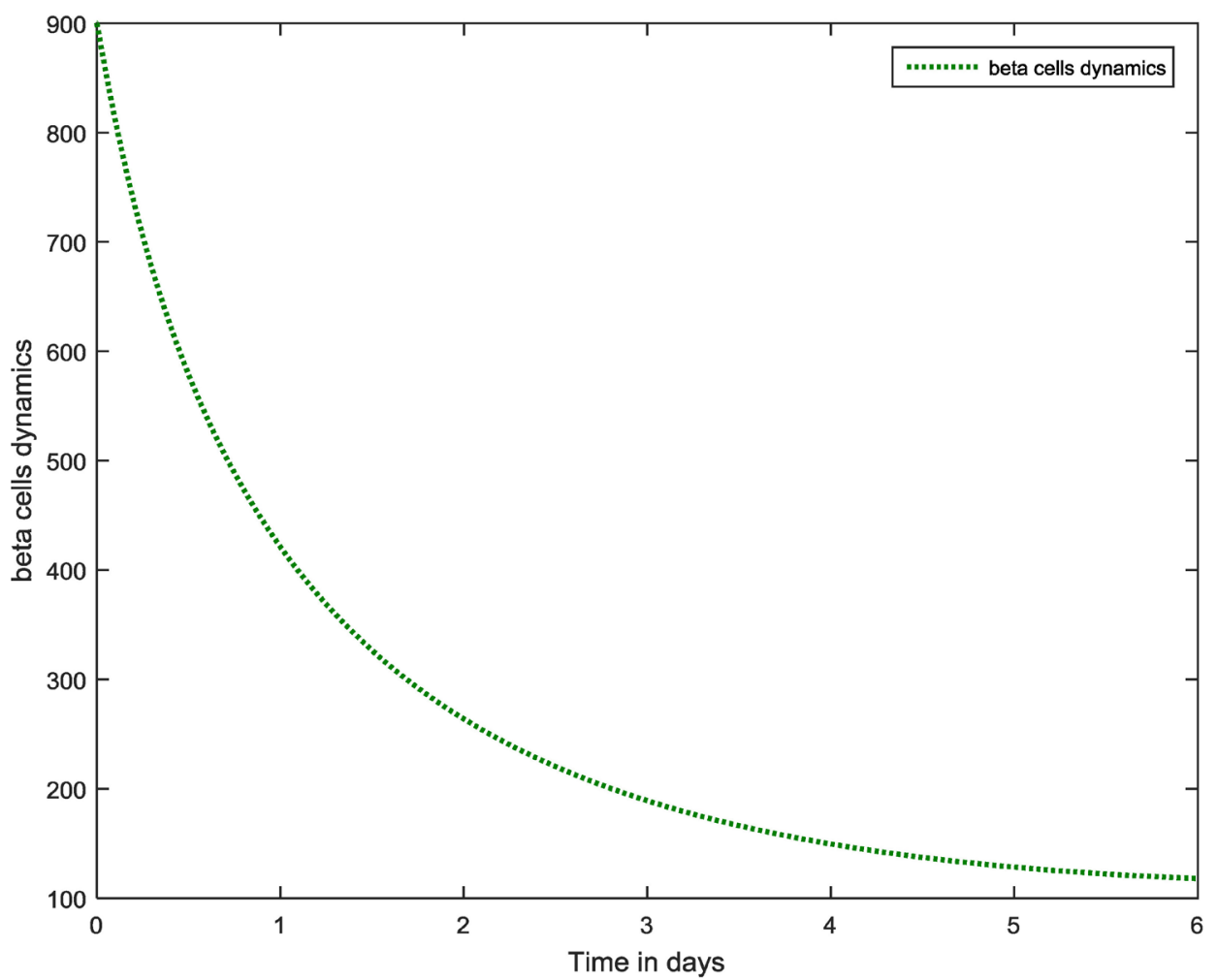

Figure 6. $\beta$-cells dynamics in the absence and presence of epinephrine 
Existing model

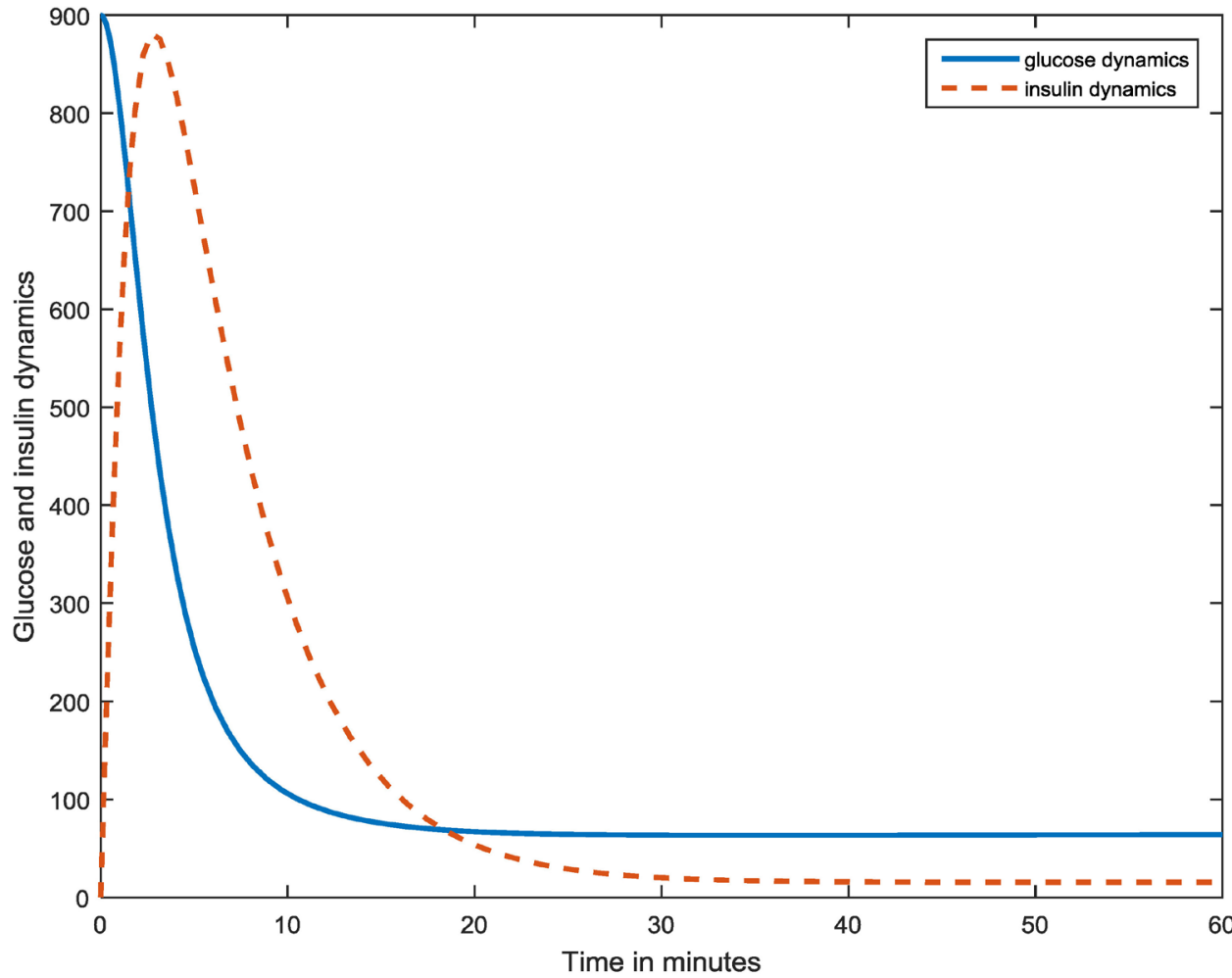

Figure 7. Glucose and insulin dynamics in the absence of epinephrine at $\beta=300$.

Modified model

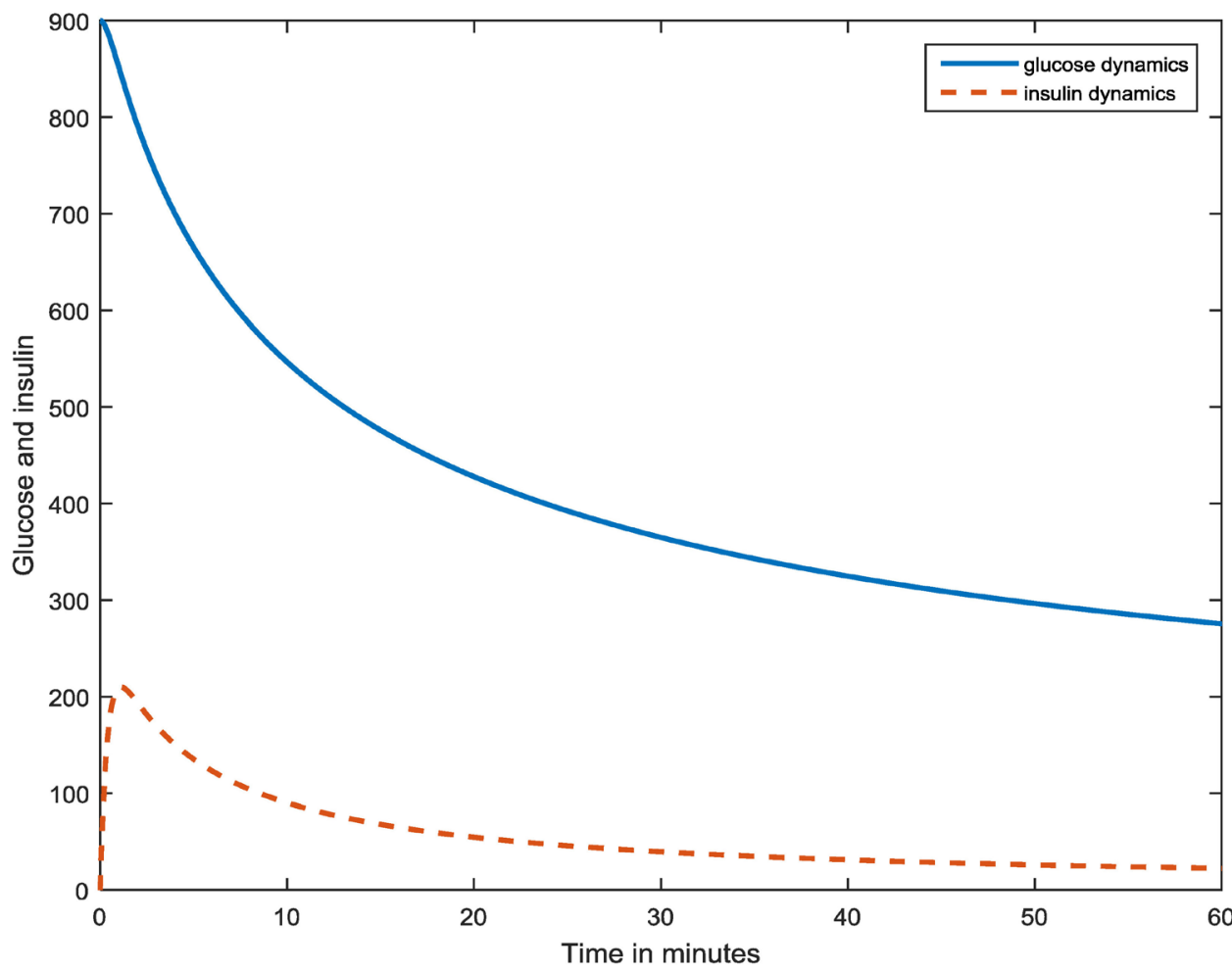

Figure 8. Glucose and Insulin dynamics in the presence of epinephrine at $\beta=300$. 
Existing model

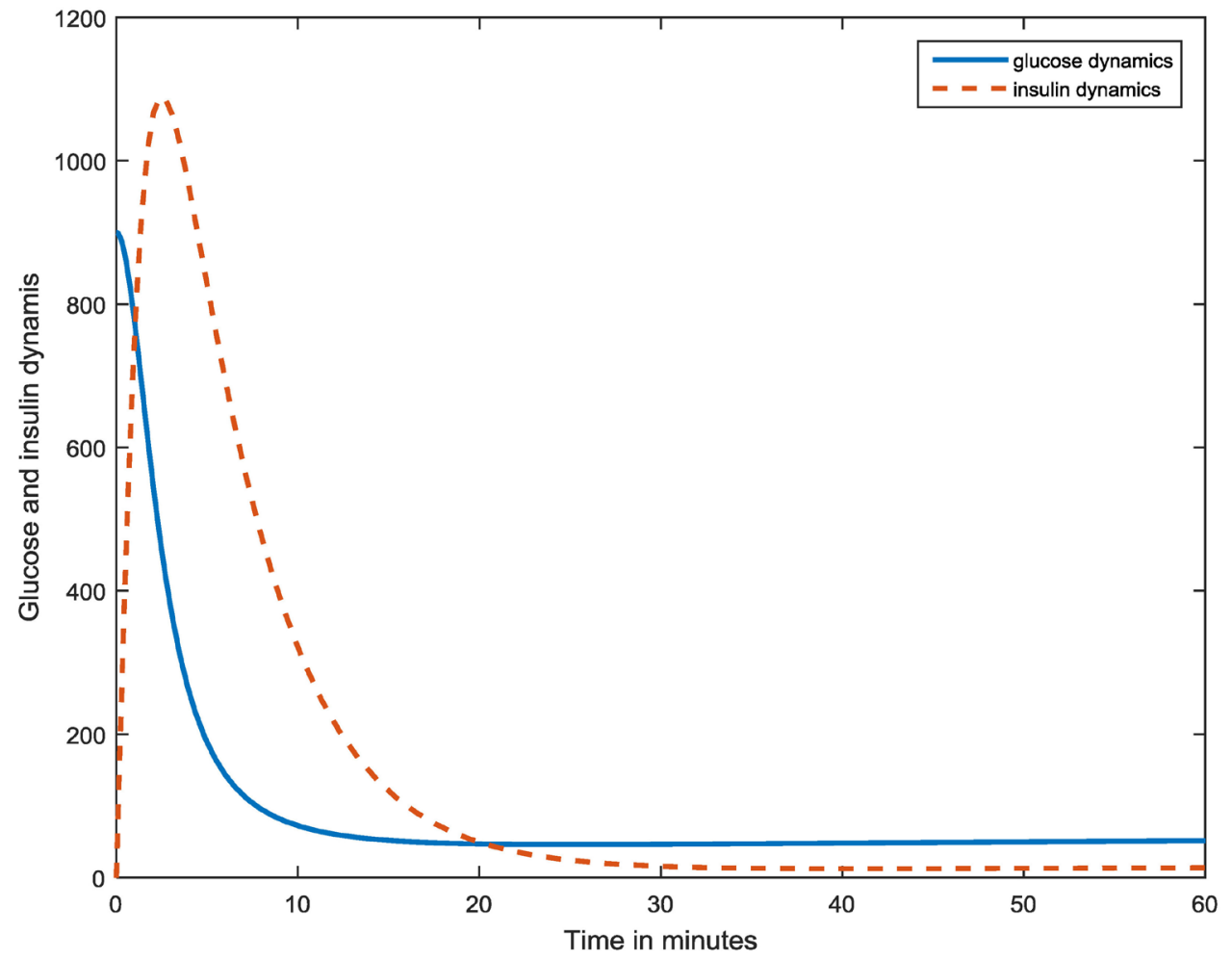

Figure 9. Glucose and Insulin dynamics in the absence of epinephrine at $\beta=600$.

Modified model

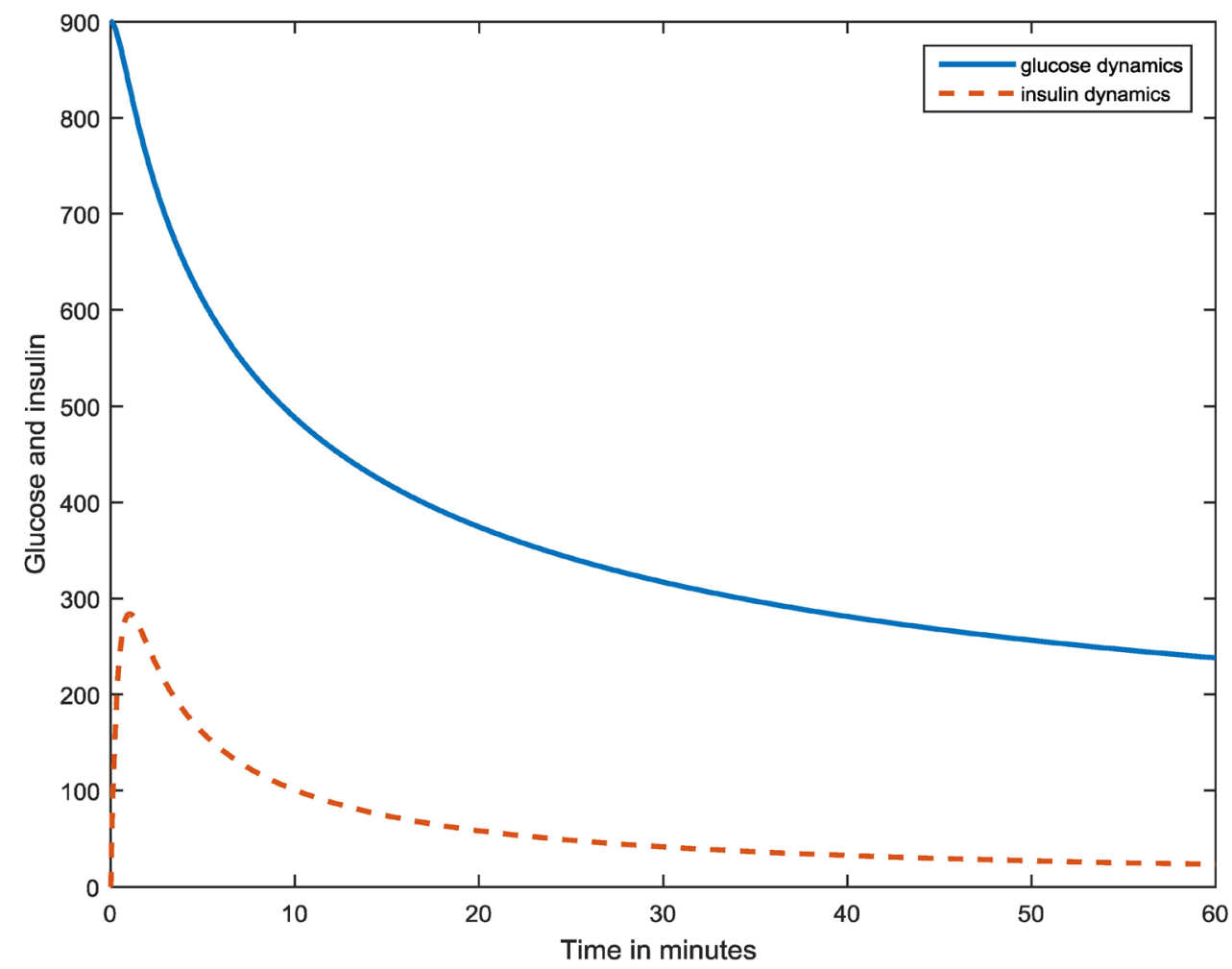

Figure 10. Glucose and Insulin dynamics in the presence of epinephrine at $\beta=600$. 
Existing model

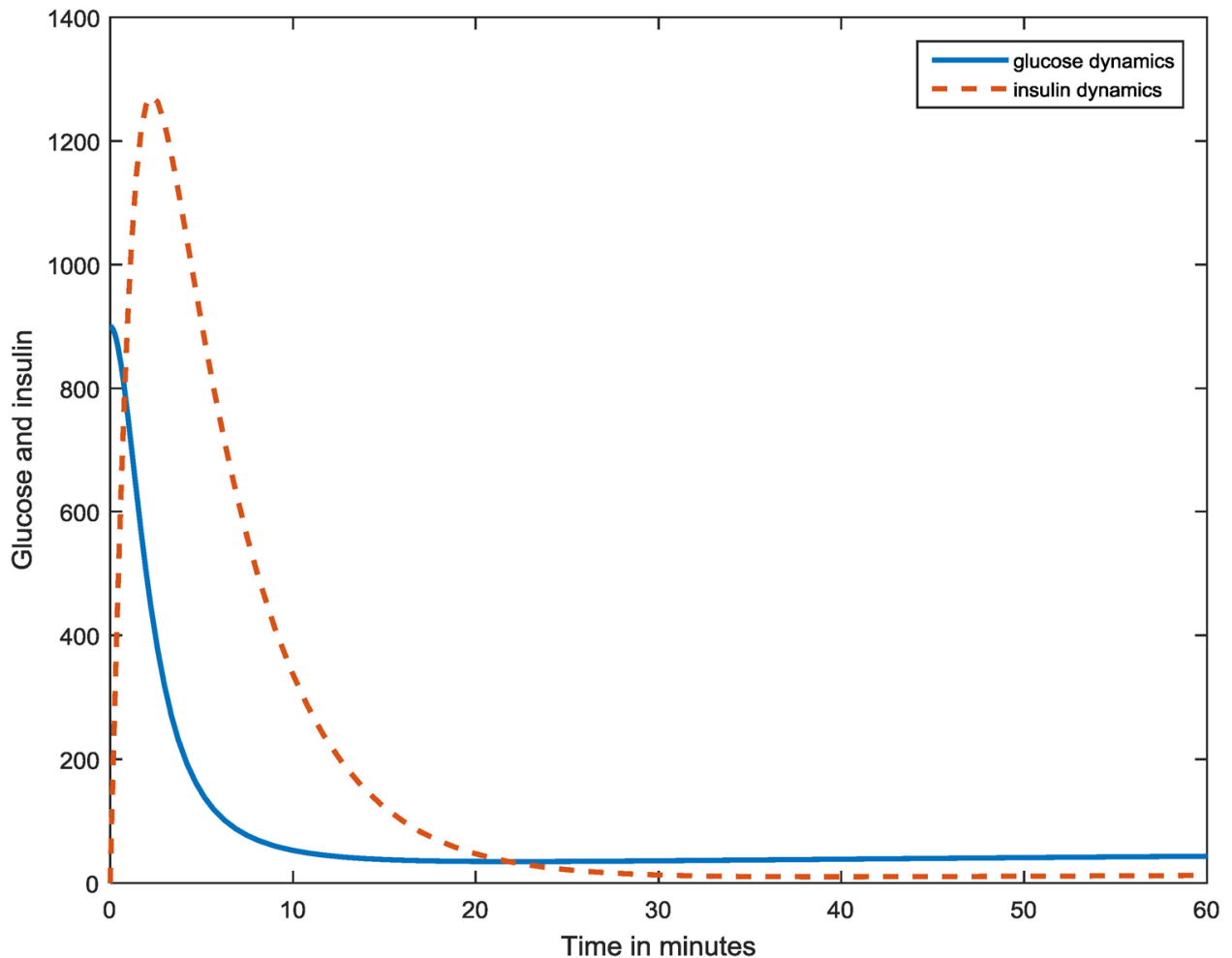

Figure 11. Glucose and Insulin dynamics in the absence of epinephrine at $\beta=900$.

\section{Modified model}

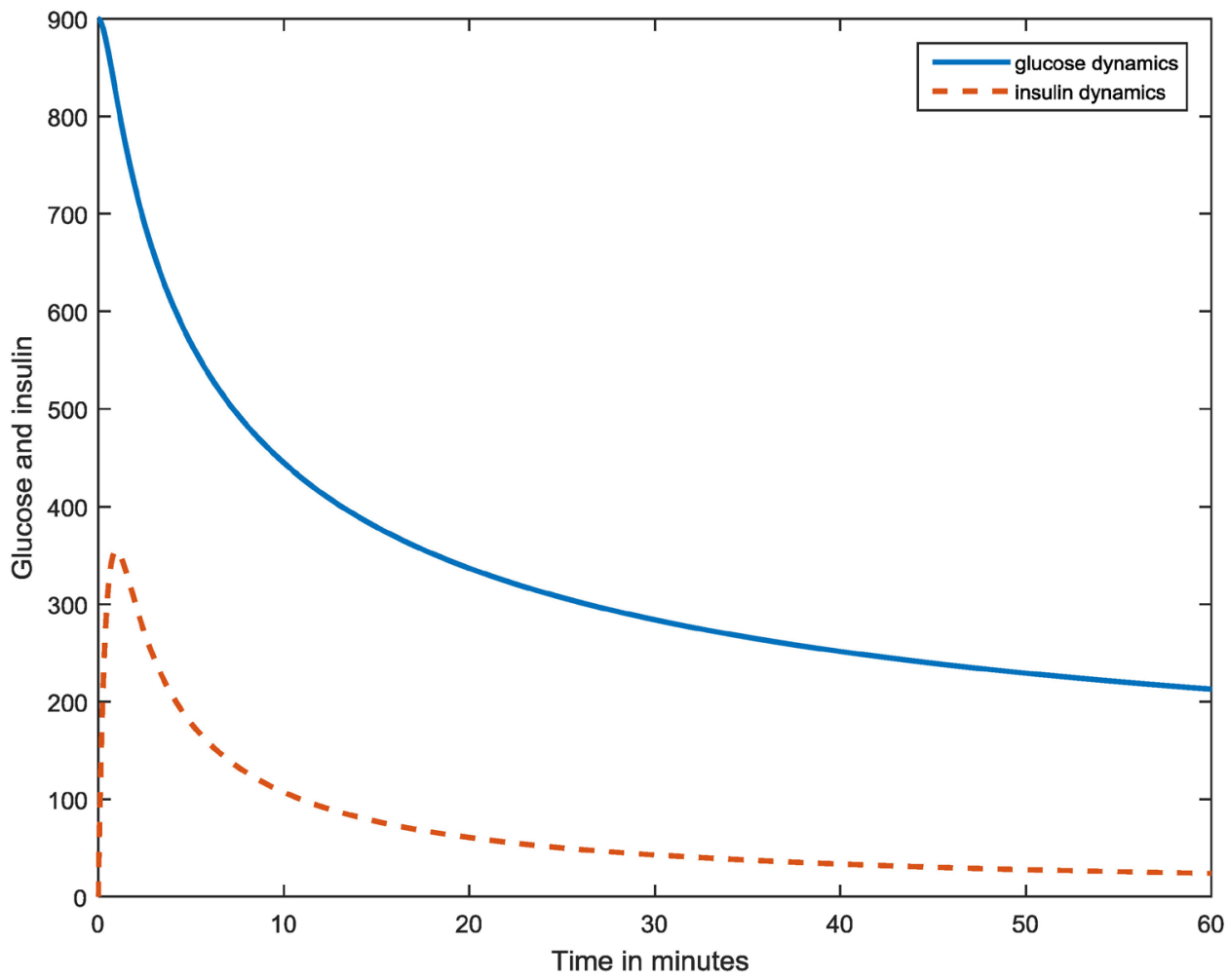

Figure 12. Glucose and Insulin dynamics in the presence of epinephrine at $\beta=900$. 
Existing model

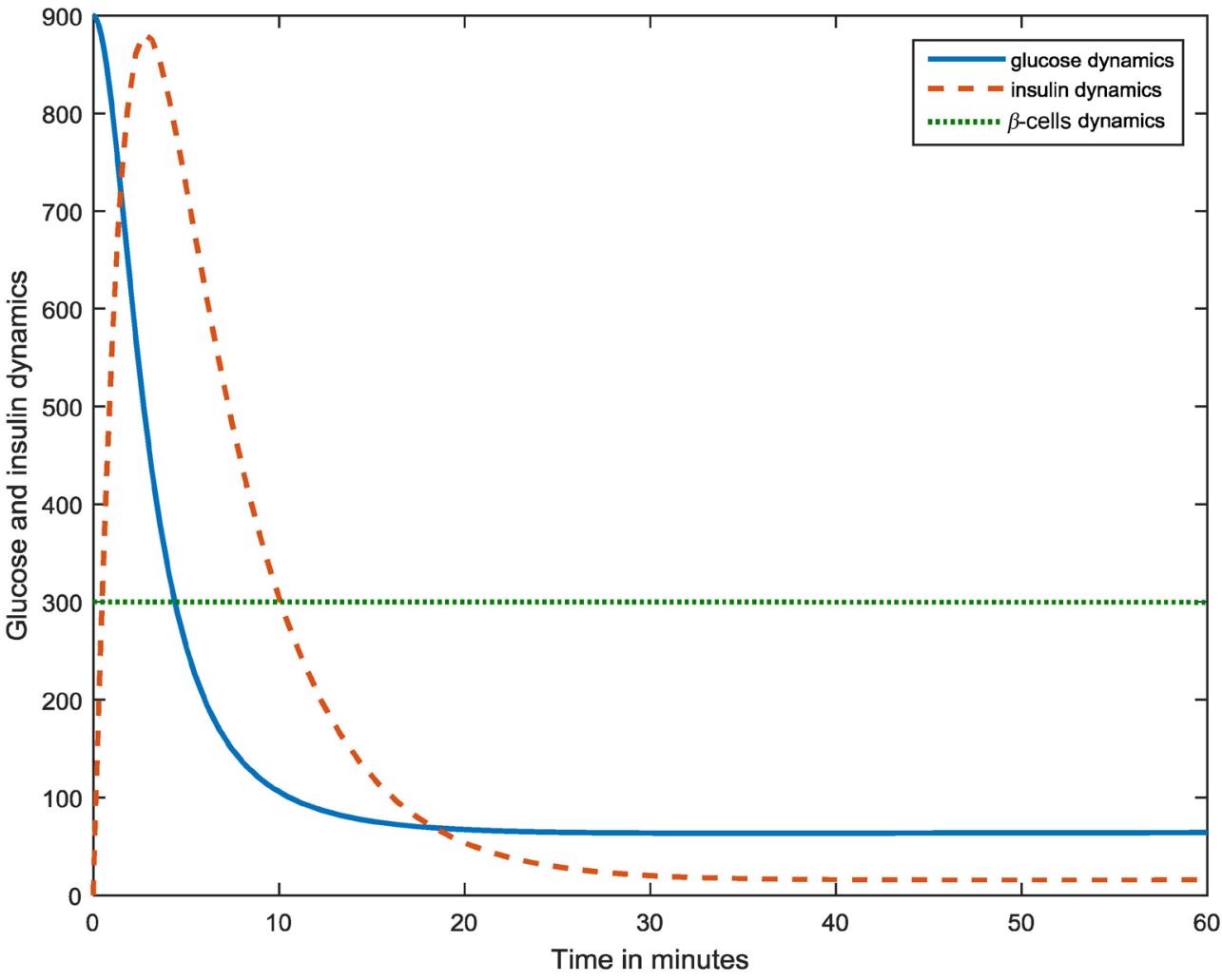

Figure 13. Glucose, Insulin and $\beta$-cell mass dynamics in the absence of epinephrine.

Modified model

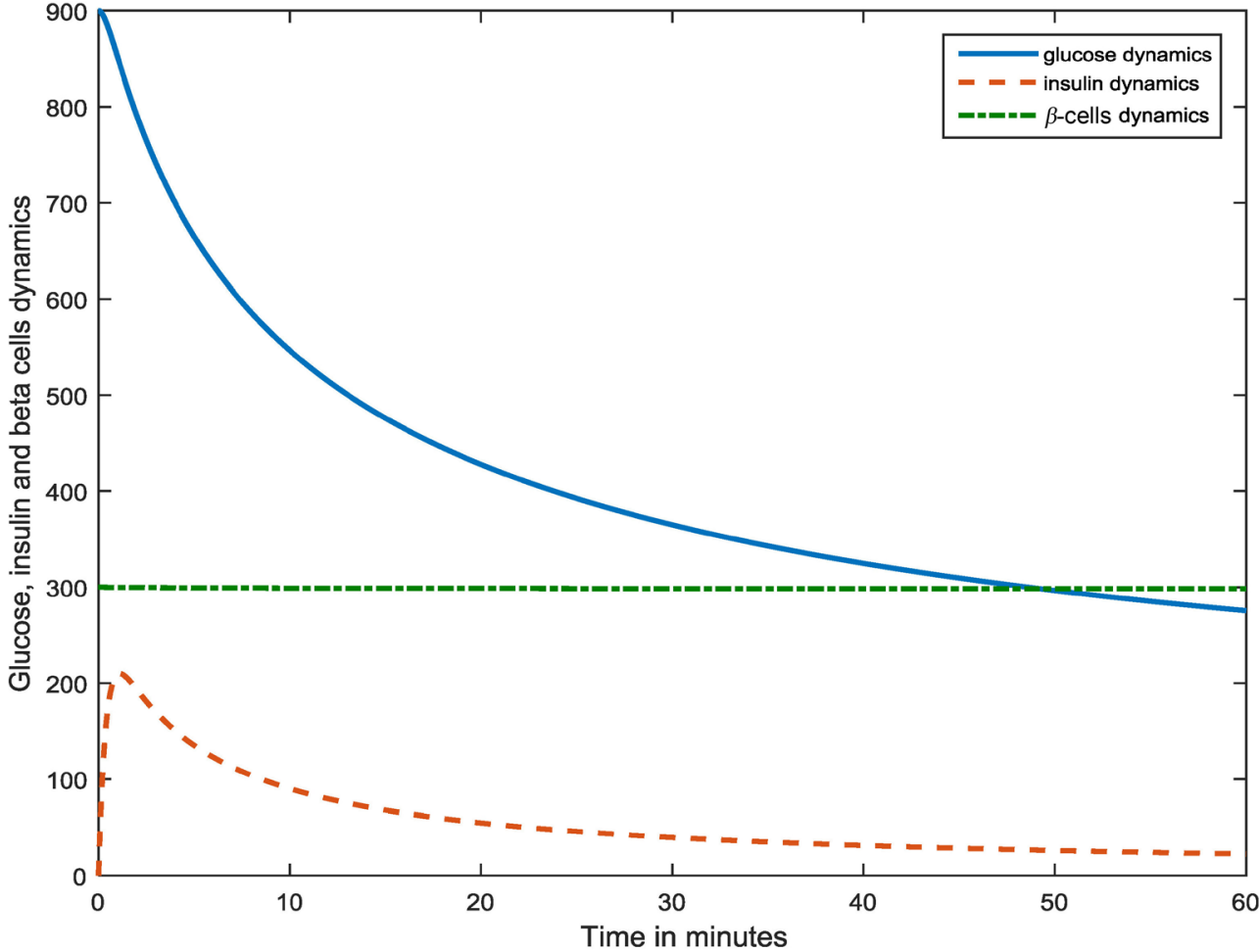

Figure 14. Glucose, Insulin and $\beta$-cell mass dynamics in the presence of epinephrine. 
Existing and modified models

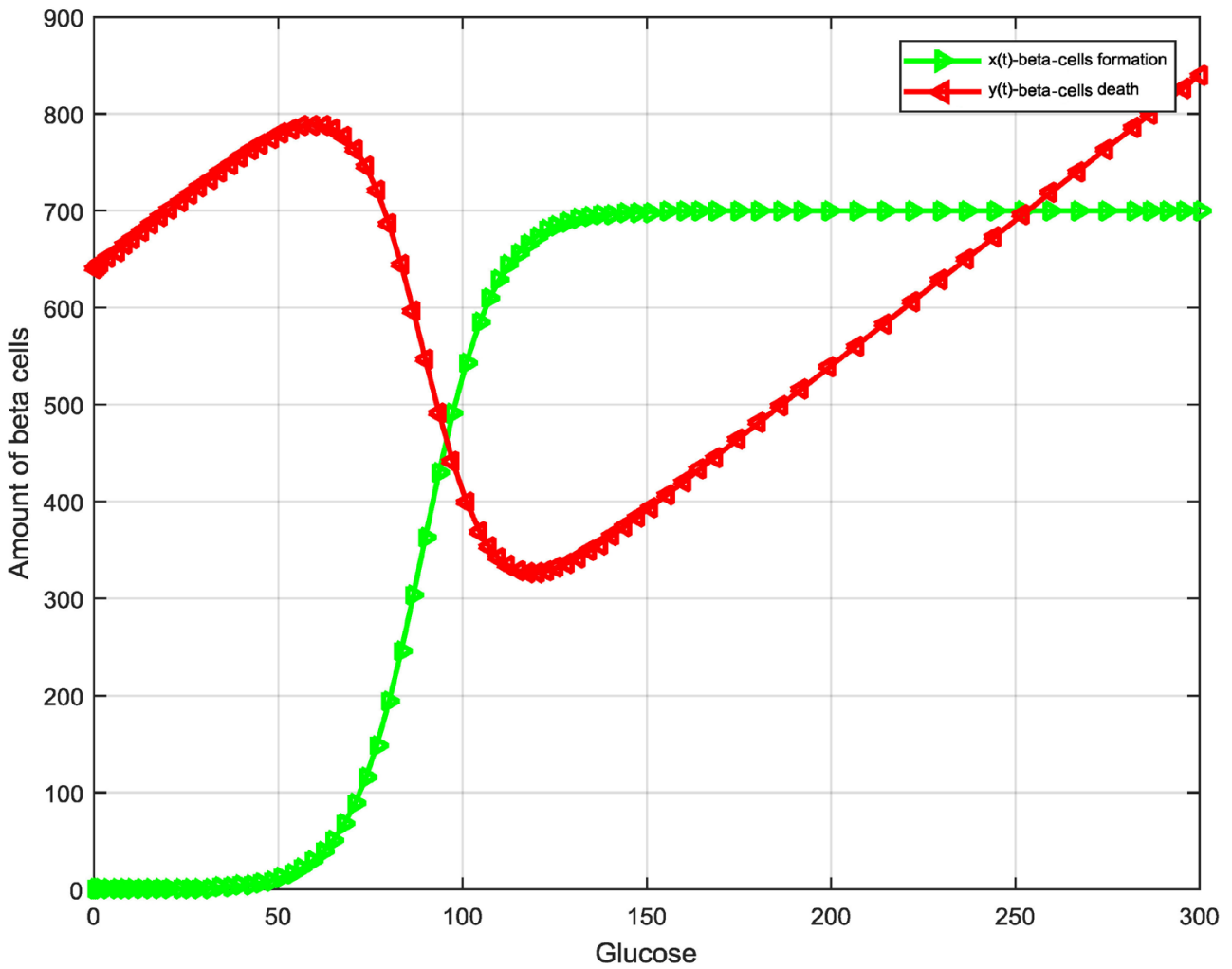

Figure 15. Dynamics of $\beta$-cell mass formation and death in the absence and presence of epinephrine.

the kidney produces epinephrine which trigger the liver to emergently produce a burst of glucose and release it into the blood.

Case 3: Insulin dynamics in the absence of epinephrine.

Figure 4 shows the insulin secretion in the absence of epinephrine from pancreatic $\beta$-cells, which follows sigmoidal function of glucose production

Case 4: Insulin dynamics in the presence of epinephrine.

Figure 5 shows the insulin secretion suppression by epinephrine which leads to low blood insulin level and increase in blood glucose level.

Case 5: $\beta$-cells dynamics in the absence and presence of epinephrine.

Figure 6 shows the dynamics of $\beta$-cell mass, mild hyperglycemia induced beta cells formation while extreme and prolong hyperglycemia induced beta cells death. At zero glucose level, beta cells formation is zero, until the glucose reached a certain level, then the formation of $\beta$-cells starts and when the glucose production is at extremely high, the beta cells death starts.

Case 6: Glucose and insulin dynamics in the absence of epinephrine at $\beta=300$.

Figure 7 shows the effect of $\beta$-cell mass on insulin secretion and glucose utilization in the absence of trauma, excitement and stress at $\beta=300$. In this glucose level is high compare to insulin level because of small amount of $\beta$-cells.

Case 7: Glucose and Insulin dynamics in the presence of epinephrine at $\beta=300$. 
Figure 8 shows the effect of $\beta$-cell mass on insulin secretion and glucose utilization in the presence of trauma, excitement and stress at $\beta=300$. In this, blood glucose level increases much higher due to blood glucose burst as a result of epinephrine and blood insulin level decreases because of the suppression on insulin secretion by epinephrine.

Case 8: Glucose and Insulin dynamics in the absence of epinephrine at $\beta=600$.

Figure 9 shows the effect of $\beta$-cell mass on insulin secretion and glucose utilization in the absence of trauma, excitement and stress at $\beta=600$. In this, glucose level decreases and blood insulin level increases because of increase in $\beta$-cell mass.

Case 9: Glucose and Insulin dynamics in the presence of epinephrine at $\beta=600$.

Figure 10 shows the effect of $\beta$-cell mass on insulin secretion and glucose utilization in the presence of trauma, excitement and stress at $\beta=600$. In this both blood glucose and blood insulin levels increase but insulin increase is insignificant to reduce blood glucose level to homeostasis due to effect of epinephrine of increasing glucose and suppression of insulin secretion.

Case 10: Glucose and Insulin dynamics in the absence of epinephrine at $\beta=900$.

Figure 11 shows the effect of $\beta$-cell mass on insulin secretion and glucose utilization in the absence of trauma, excitement and stress at $\beta=900$. In this blood glucose level decreases while the blood insulin level increases because of increase in $\beta$-cell mass population.

Case 11: Glucose and Insulin dynamics in the presence of epinephrine at $\beta=900$.

Figure 12 shows the effect of $\beta$-cell mass on insulin secretion and glucose utilization in the presence of trauma, excitement and stress at $\beta=900$. In this the blood glucose level remain high while insulin level increase but not enough to reduce blood glucose level to homeostasis.

Case 12: Glucose, Insulin and $\beta$-cell mass dynamics in the absence of epinephrine.

Figure 13 shows the dynamics of glucose, insulin and $\beta$-cell mass in the absence of trauma, excitement and stress. Blood glucose level decreases, blood insulin level increases while the $\beta$-cell mass remain constant.

Case 13: Glucose, Insulin and $\beta$-cell mass dynamics in the presence of epinephrine.

Figure 14 shows the dynamics of glucose, insulin and $\beta$-cell mass in the presence of trauma, excitement and stress. Blood glucose level increases, blood insulin level decreases while $\beta$-cell mass remain constant due to presence of epinephrine. This indicated that there is no effect of epinephrine on $\beta$-cell mass.

Case 14: Dynamics of $\beta$-cell mass formation and death in the presence of epinephrine.

Figure 15 shows the effect of glucose on beta cells formation and death in the presence of trauma, excitement and stress. 
The effects of epinephrine on three pathways to diabetic state are as followed:

Effect of epinephrine on Regulated Hyperglycemia; in this beta-cells death is greater than formation. This will push glucose to high level in addition to the blood glucose burst from liver because of epinephrine secretion and low blood insulin due to suppression by epinephrine hormone.

Effect of epinephrine on Bifurcation; in this, beta cells formation is greater than death which lead to high blood insulin and low blood glucose level but due to presence of epinephrine, the insulin secretion would be suppressed and blood glucose level will be increased. This will make blood glucose to remain at high level as a result of low insulin.

Effect of epinephrine on Dynamical Hyperglycemia; in this beta cells death is extremely greater than beta cells formation which lead to extreme elevated blood glucose level due extremely low insulin in addition to the burst in blood glucose due the epinephrine and low blood insulin level due to suppression by epinephrine hormone which will further increase blood glucose level and decrease blood insulin level.

Therefore, from the above discussion we understood that trauma, excitement and stress increased blood glucose level and decrease blood insulin level while in other side trauma, excitement and stress have no effect on beta cells formation and lost.

During the experiments three distinct amount of beta cell masses: 300, 600 and 900 were used. The result showed that in normal condition, beta-cell mass had significant effect in glucose utilization. However, in the presence of trauma, excitement and/or stress, the amount of beta cell mass had less effect in glucose utilization because of epinephrine suppression on insulin secretion. Beta cell mass increased blood insulin level but not enough to trigger more glucose utilization in such a way that will bring down the blood glucose level into homeostasis even with high number of beta cell mass 900 . According to [11], the average mass of $\beta$-cell mass in a normal individual has been found to be $850 \mathrm{mg}$. This means in the presence of epinephrine the blood glucose level remains high despite the fact that there is increase in beta cell mass.

The model developed which was an extension of [1] model is similar to those of, [4] [12] and [11] for glucose, insulin, and $\beta$-cell mass kinetics. However, it differs significantly by its peculiarity in the case of epinephrine hormone which is secreted by adrenal medulla of the kidney for taking care of emergency condition cause by trauma, excitement and/or stress which increase blood glucose level.

The results of equilibrium analysis showed that the fast subsystem and slow subsystem were independently locally and asymptotically stable since the Eigen values of both the systems were negatives. Analyzing the system as a whole, the system was locally and asymptotically stable.

All the three pathways to diabetes state would be affected by epinephrine hormone because of its effect on increase in blood glucose level and decrease in blood insulin level. This showed that trauma, excitement and stress increase the risk of extreme and prolong hyperglycemia. 


\subsection{Summary, Conclusion and Recommendation}

In this work, we incorporated a parameter $\rho$ by defining it as effectiveness of epinephrine in suppressing insulin secretion and a parameter $G_{e}$ by defining it as epinephrine induced glucose increase as the factors that affect glucose and insulin homeostasis. The model which consists of a system of three nonlinear ordinary differential equations was used to investigate the effect of epinephrine on glucose, insulin and beta cell mass dynamics. The result of the study showed that; in the presence of epinephrine there is increase in blood glucose level and increase in Beta cell mass which increase blood insulin level but not enough to bring down blood glucose level into homeostasis. As a result of that, there is an extreme hyperglycemia in all three distinct states. Furthermore, the result of the numerical experiment carried out indicated that frequent epinephrine secretion into the blood induced prolong and extreme hyperglycemia. An extreme hyperglycemia induced both beta cells death and insulin resistance which would lead to diabetes. In conclusion, frequent state of trauma, excitement and/or stress induced diabetes. In view of the findings of this study, we recommended that there should be a massive and continuous health education especially for communities living in the areas where the stated agents (trauma, excitement and stress) of epinephrine secretion are common, so that the people will understand the effect of these agents on their healthy living and this will minimize the occurrence of diabetic among the people. The government, non-governmental organization and public health workers should focus on public enlightenment programs aimed at enabling individuals in the society to understand how these three factors increase the risk of having diabetes in their lives.

\subsection{Conclusion}

We modified [10] mathematical model for beta-cell mass, insulin and glucose kinetics by incorporating the parameter " $G_{e}$ " and " $\rho$ " as the rate of glucose production due to epinephrine secretion and epinephrine effectiveness in suppressing insulin secretion to examine the effect of two parameters on glucose regulatory system. Analytical studies were carried out using Jacobian matrix. The equilibrium points were obtained and our results showed that the equilibrium point of the system is locally asymptotically stable since all the Eigen values were negative; this showed that the disease will be controlled to avoid further spread. The result of the numerical experiment carried out indicated that frequent epinephrine secretion into the blood induced prolong and extreme hyperglycemia. An extreme hyperglycemia induced both beta-cells death and insulin resistance which can lead to both type 1 and type 2 diabetes.

\section{Conflicts of Interest}

The authors declare no conflicts of interest regarding the publication of this paper. 


\section{References}

[1] Topp, B., Promislaw, K., de Vries, G., Miura, R. and Finegood, D. (2000) A Model of $\beta$-Cell Mass, Insulin, and Glucose Kinetics: Pathways to Diabetes. Journal of Theoretical Biology, 206, 605-619. https://doi.org/10.1006/jtbi.2000.2150

[2] Kwacha, B., Ongati, O. and Simwa, R. (2011) Mathematical Model for Detecting Diabetes in the Blood. Applied Mathematical Sciences, 5, 279-286.

[3] Ahlam, A.S. and Alaa, S. (2014) Developing a Mathematical Model to Detect Diabetes Using Multigene Genetic Programming. Advance Journal in Artificial Intelligence, 3, 54-59. https://doi.org/10.14569/IJARAI.2014.031007

[4] Boutayeb, A., Chetouani, A., Achouyab, K. and Twizell, E.H. (2004) Mathematical Model for the Burden of Diabetes and Its Complications. Biomed Engineering Online, 3, 20. https://doi.org/10.1186/1475-925X-3-20

[5] David, C. and Ralph, A. (1980) Epinephrine Induced Insulin Resistance in Man. Journal of Clinical Investigation, 65, 717-721. https://doi.org/10.1172/JCI109718

[6] Laurent, D., Petersen, K.F., Russell, R.R., Cline, G.W. and Shulman, G.I. (1998) Effect of Epinephrine on Muscle Glycogenolysis and Insulin Stimulated Muscle Glycogen Synthesis in Human. American Journal of Physiology, 274, E130-E138.

[7] Frank, N. and Mingxian, J. (2015) Mathematical Modelling and Simulations of the Pathophysiology of Type 2 Diabetes Mellitus. 8th International Conference on Biomedical Engineering and Informatics, Shenyang, 14-16 October 2015, 296-300.

[8] Hussain, J. and Zadeng, D. (2014) Mathematical Model of Glucose Insulin Interaction. Science Vision, 14, 84-88.

[9] Termitope, O. (2016) Current Trends in Preventing Diabetes. Pharmnews, 38, 11.

[10] https://biogearsengine.com/documentation/_endocrine_methodology.html

[11] Ryan, D., Danielle, J.L., Daniel, B.R., Thomas, B.V. and Stephen, A.W. (2001) Model of $\beta$-Cell Mass, Insulin, Glucose, and Receptor Dynamics with Application to Diabetes. Cornel Univ. Dept. of Biometric Technical Report BU-1579-M.

[12] Ibrahim, I.A., Haruna, Y. and Garba, E.J.D. (2014) Mathematical Model for the Dynamics of Glucose Regulatory System under the Combined Effect of Dieting and Physical Activity. International Journal of Pure and Applied Science and Technolo$g y, 20,88-100$. 